\title{
Synthesis and Faraday Effect of Fe-Al Oxide Composite Ferrofluid
}

\author{
Min Dai1,2, Shengli Pu \\ ${ }^{1}$ College of Mining, University of Guizhou for Project and Application Technology, Guizhou, China \\ ${ }^{2}$ College of Science, University of Shanghai for Science and Technology, Shanghai, China \\ Email: daiminshh@aliyun.com
}

Received 24 July 2015; accepted 24 August 2015; published 27 August 2015

Copyright (C) 2015 by authors and Scientific Research Publishing Inc.

This work is licensed under the Creative Commons Attribution International License (CC BY).

http://creativecommons.org/licenses/by/4.0/

c) (i) Open Access

\begin{abstract}
A kind of ferrofluid containing Fe-Al oxide composite nanometer particles was synthesized. The ferrofluid made of Fe-Al oxide composite nanometer particles which ratio was $\mathrm{Fe}: \mathrm{Al}_{2} \mathrm{O}_{3}=3: 1$ and thermally treated at $300^{\circ} \mathrm{C}$ showed Faraday effect approximate linearity versus the magnetic field $B$, and a relatively excellent Faraday effect without saturation in varying 0 - 1.5T magnetic field, which provided a method for synthesizing the ferrofluid of Faraday rotation still continuing in a relatively high magnetic field.
\end{abstract}

\section{Keywords}

Faraday Effects, Ferrofluid, Fe-Al Oxide Composite Nanometer particles, Saturation

\section{Introduction}

Faraday effect is the rotation of polarization plane of the linearly polarized light due to magnetic field induced circular birefringence of a material, which depends on the incident light wavelength and the structure of the material. The rotation angle $\theta=\pi(\Delta \mathrm{n} / \lambda) \mathrm{L}$, where $\Delta \mathrm{n}$ is the index difference between the left and right circularly polarized light, $\lambda$ is the wavelength of the incident light and $\mathrm{L}$ is the length of the sample along magnetic field direction. Faraday active materials are often used to fabricate many optical devices and sensors, such as optical isolators [1], optical information storage devices [2], and highly sensitive magnetic field sensors [3] [4]. Measurements of Faraday effect have also been used to determine the electron concentration and its profile in semiconductors where the effective mass of the carrier is known [5]. Researchers continue to discover and synthesize new Faraday active materials to expect more extensive applications of Faraday effects in many areas. At present, researchers have synthesized a lot of films, glasses and crystals with Faraday effects [6]-[9]. Synthesizing various new nanometer materials with excellent Faraday effects is ongoing. 
Ferrofluid is a kind of colloid containing surfactant coated nanometer particles dispersed in a carrier liquid. It is a macro-symmetrical system under zero external magnetic fields. When it is placed in a magnetic field, aggregations of magnetic particles elongated along the field direction happen due to the strong inter-particle interactions [10]-[12]. Then, the ferrofluid becomes an anisotropic system. This makes the ferrofluid to have the properties similar to those of nematic liquid crystals. If the light pass through the ferrofluid placed in a magnetic field, several excellent optical effects will happen, such as linear dichroism, linear birefringence and Faraday effects. Researchers found that Faraday rotation of the ferrofluid placed in a magnetic field is governed by both the magnetization and particle chain formation [13]. Faraday rotation also depends on the particle size (for particle diameters ranging from 1 to $100 \mathrm{~nm}$ ) and the inter-particle distance [14]. Janssen et al. mentioned that the scattering of the permanent magnetic moment in ferrofluid placed in magnetic field would lead to a new description of the Faraday rotation and the circular dichroism [15]. If a polarized light passes through the ferrofluid along the direction of magnetic field, an excellent Faraday effect is observed [16]-[18], which usually follows a Langevin type behavior [16] [19]. Faraday effect saturate at high magnetic field limits the applications of ferrofluid in high magnetic fields.

Chemical coprecipitation with ferrous and ferric solutions as raw materials is the typical method for synthesizing ferrofluids [20]-[22]. But chemical coprecipitation method can only be utilized to synthesize few types of ferrofluids. Sol-gel technique can tailor the diameter of the particles by controlling the process and ingredients, which has several advantages for making inorganic composite materials containing highly dispersed magnetic oxide particles. Since the process usually starts from liquid raw materials, the sources of magnetic ions/particles such as ferric or ferrous salts can be easily mixed with the source of matrix homogeneously at molecule level at the beginning of the synthesizing.

In this work, the Fe-Al oxide composite ferrofluid was synthesized by sol-gel technique. After gelling and calcining, the iron oxide and aluminum elements were synthesized into composite particles. The composite magnetic particles ferrofluid in this work are different from $\mathrm{Fe}_{3} \mathrm{O}_{4}$ magnetic particles. This type of compose particle ferrofluid is little reported. The element difference of magnetic particles for ferrofluid may lead to the ferrofluid arising new physical properties. In this experiment, the Faraday effect was observed in the as-prepared Fe-Al oxide composite ferrofluid. The phenomenon of saturation of Faraday effect of Fe-Al-O composite particle ferrofluid at high magnetic field does not happen. It will undoubtedly initiate a wider prospect for ferrofluid applications.

\section{Experiment}

\subsection{Synthesizing Fe-Al oxide Composite Particles}

To synthesize the Fe-Al oxide composite ferrofluid, Fe-Al oxide composite magnetic particles were firstly prepared by sol-gel technique using the method in Ref. 23. Two kinds of sols were prepared using the raw materials as shown in Table 1.

Table 1. Raw materials for preparing the sols.
\begin{tabular}{|ccccccc} 
Type of sol & $\begin{array}{c}\text { Type of solute } \\
(\mathrm{wt} / \mathrm{wt})\end{array}$ & $\begin{array}{c}\text { Mass of solute } \\
(\mathrm{g})\end{array}$ & $\begin{array}{c}\text { Type of solvent } \\
(\mathrm{v} / \mathrm{v})\end{array}$ & $\begin{array}{c}\text { Volume of solvent } \\
(\mathrm{ml})\end{array}$ & $\begin{array}{c}\text { Catalyst } \\
(\mathrm{v} / \mathrm{v})\end{array}$ & $\begin{array}{c}\text { Volume of sols } \\
(\mathrm{ml})\end{array}$ \\
\hline Fe-sol & $\begin{array}{c}\mathrm{Fe}\left(\mathrm{NO}_{3}\right)_{3} \cdot 9 \mathrm{H}_{2} \mathrm{O}(\geqq 98 \%) \\
\mathrm{Al}_{\left(\mathrm{C}_{3} \mathrm{H}_{7} \mathrm{O}\right)_{3}}\end{array}$ & 35.6 & $\mathrm{H}_{2} \mathrm{O}(100 \%)$ & 200 & $\mathrm{HNO}_{3}(65 \%-68 \%)$ & 10 \\
$\left(\mathrm{Al}_{2} \mathrm{O}_{3} \geqq 27 \%\right)$ & 12.5 & $\mathrm{C}_{2} \mathrm{H}_{5} \mathrm{OH}(100 \%)$ & 500 & $\mathrm{HNO}_{3}(65 \%-68 \%)$ & 25 \\
\hline
\end{tabular}

The Fe-sol was prepared at room temperature (approximately $30^{\circ} \mathrm{C}$ ) and the $\mathrm{Al}$-sol was prepared at $90^{\circ} \mathrm{C}$. The catalyst was dropped into the sols and stirred by a magnetic-force mixer. The composite sols were thermally treated in a resistance oven before dried into gels. The composition gels of $\mathrm{Fe} / \mathrm{Al}_{2} \mathrm{O}_{3}$ were thermally treated. The temperature was raised at a proper velocity. In our experiments, the temperature was raised in speed of $5^{\circ} \mathrm{C} / 15$ minutes. The mass ratio of Fe: $\mathrm{Al}_{2} \mathrm{O}_{3}=3: 1,2: 1,1: 1,1: 2$ and 1:3, respectively. Each sample was thermally treated at $300^{\circ} \mathrm{C}, 400^{\circ} \mathrm{C}, 500^{\circ} \mathrm{C}, 600^{\circ} \mathrm{C}, 700^{\circ} \mathrm{C}, 800^{\circ} \mathrm{C}$ and $900^{\circ} \mathrm{C}$, respectively.

\subsection{Preparing Fe-Al Oxide Ferrofluid and Faraday Rotation Measurement}

The Fe-Al oxide composite magnetic particles were dispersed into $1 \mathrm{ml}$ oleic acid $\left(\mathrm{C}_{18} \mathrm{H}_{34} \mathrm{O}_{2}\right)$ and then put into a 
tube with ultrasonic agitation for 10 minutes. Then, $10 \mathrm{ml}$ paraffin liquid was poured into the solution and the mixture was agitated with ultrasound for another 30 minutes. Finally, the Fe-Al oxide composite ferrofluid was obtained. After three days, the $\mathrm{Fe}-\mathrm{Al}$ oxide composite ferrofluid was employed for Faraday measurement by the standard light extinction method [23]. The ferrofluid of valid optical path (the size of light to pass through) is 10 $\mu \mathrm{m}$ order of magnitude. Details about the Faraday measurement were reported [24].

\section{Results and Discussion}

Figure 1 is the experimental results of the Faraday rotation of the Fe-Al oxide composite ferrofluid. In Figure 1,

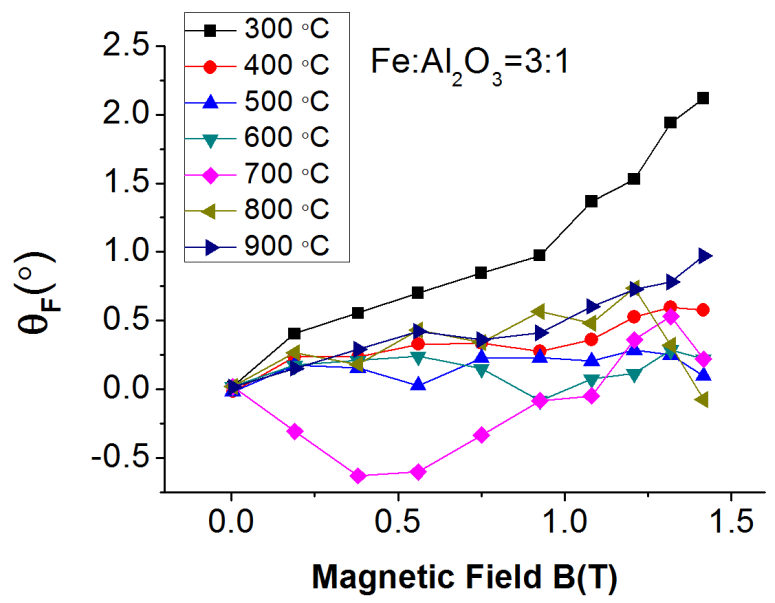

(a)

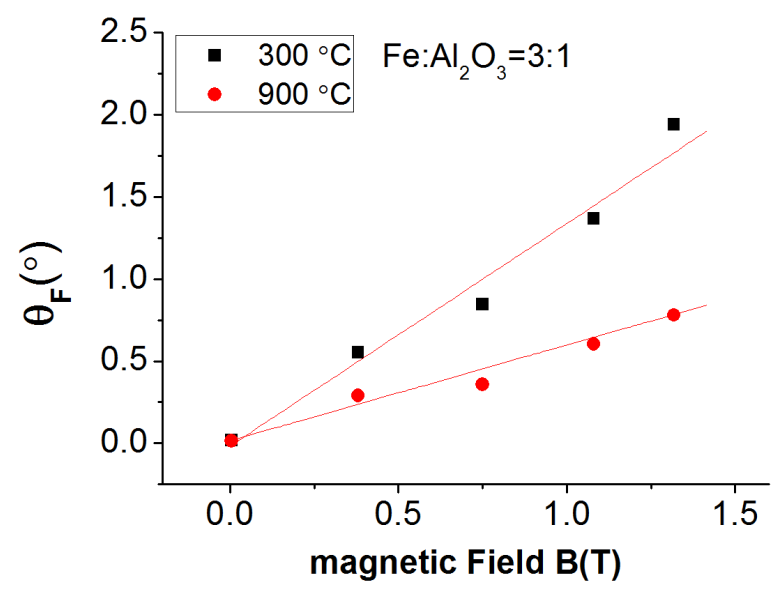

(b)

Figure 1. Faraday effects of the Fe-Al oxide composite ferrofluid. The composite particles were thermally treated at several different temperatures: $300^{\circ} \mathrm{C}, 400^{\circ} \mathrm{C}, 500^{\circ} \mathrm{C}, 600^{\circ} \mathrm{C}$, $700^{\circ} \mathrm{C}, 800^{\circ} \mathrm{C}$ and $900^{\circ} \mathrm{C}$, respectively.

the transverse axis indicates the used magnetic field $\mathrm{B}$, and the longitudinal axis indicates the Faraday rotation angle degree of sample. The Fe-Al oxide composite particles have a mass ratio of $\mathrm{Fe}_{\mathrm{Al}} \mathrm{Al}_{2} \mathrm{O}_{3}=3: 1$ and thermally treated at $300^{\circ} \mathrm{C}, 400^{\circ} \mathrm{C}, 500^{\circ} \mathrm{C}, 600^{\circ} \mathrm{C}, 700^{\circ} \mathrm{C}, 800^{\circ} \mathrm{C}$ and $900^{\circ} \mathrm{C}$, respectively. In Figure 1 (a), the Faraday rotation curve of ferrofluid with $\mathrm{Fe}-\mathrm{Al}$ oxide particles treated thermally at $300^{\circ} \mathrm{C}$ has a relatively excellent Faraday effect than other samples, the curve increases more rapid than others. The Faraday rotation curves of ferrofluid with $\mathrm{Fe}-\mathrm{Al}$ oxide particles treated thermally at $400^{\circ} \mathrm{C}, 500^{\circ} \mathrm{C}, 600^{\circ} \mathrm{C}$ and $900^{\circ} \mathrm{C}$ are also approximate linearity, but the Faraday rotation angle is too small to apply at aspect of Faraday rotation. For clear interpretation, Figure 1(b) is given. In Figure 1(b), the straight lines are fitting curves, and the symbol curves are experiment data 
curves. The Faraday rotation curve of ferrofluid with Fe-Al oxide particles treated thermally at $900^{\circ} \mathrm{C}$ is selected among these curves, for it is approximate linearity and has approximate slope versus Faraday rotation curves of ferrofluid with $\mathrm{Fe}-\mathrm{Al}$ oxide particles treated thermally at $400^{\circ} \mathrm{C}, 500^{\circ} \mathrm{C}, 600^{\circ} \mathrm{C}$. According to Figure 1(b), the Faraday rotation angle degree of ferrofluid with $\mathrm{Fe}-\mathrm{Al}$ oxide particles treated thermally at $300^{\circ} \mathrm{C}$ is $1.35516^{\circ} / \mathrm{T}$ and the Faraday rotation angle degree of ferrofluid with Fe-Al oxide particles treated thermally at $900^{\circ} \mathrm{C} 0.58336^{\circ} / \mathrm{T}$. The Faraday rotation curves of ferrofluid with Fe-Al oxide particles treated thermally at $700^{\circ} \mathrm{C}, 800^{\circ} \mathrm{C}$ are non-linearity, this phenomenon required further study. The Faraday rotation curves of ferrofluid which Fe-Al oxide composite particles have a mass ratio of $\mathrm{Fe}: \mathrm{Al}_{2} \mathrm{O}_{3}=1: 1,1: 2,1: 3,2: 1$ and 3:1 and thermally treated at $300^{\circ} \mathrm{C}$ are discussed further. In the pure $\mathrm{Fe}_{3} \mathrm{O}_{4}$ particle ferromagnetic media, the Faraday rotation has a non-linear dependence on magnetic field in normal temperature region [13]. In this experiments, the charts in Figure 1 interpret that Faraday rotation has a approximate linear dependence on magnetic field in normal temperature region may done (except the chart of $700^{\circ} \mathrm{C}$ and $800^{\circ} \mathrm{C}$ treated magnetic particles ferrofluid). The Faraday effect of ferrofluid containing Fe-Al oxide particles with mass proportion of $\mathrm{Fe}: \mathrm{Al}_{2} \mathrm{O}_{3}$ $=3: 1$ thermally treated at $300^{\circ} \mathrm{C}$ does not saturate at high magnetic field in our experiments. It was suggested by Nihad A. Yusuf et al. that Faraday effect had a saturation onset at fields $2000 \mathrm{G}$ and have not reached saturation in field up to $4000 \mathrm{G}$ for diluted (Ms $=20 \mathrm{G}$ ) $\mathrm{Fe}_{3} \mathrm{O}_{4}$ particle ferrofluid with diester as a carrier liquid [18]. In this paper, the $\mathrm{Fe}_{3} \mathrm{O}_{4} / \mathrm{Fe}_{2} \mathrm{O}_{3} / \mathrm{Al}_{2} \mathrm{O}_{3}$ particle [25] ferrofluid was used, such diluted particle ferrorfluids containing $\mathrm{Fe}-\mathrm{Al}$ oxide particles ( $\left.\mathrm{Fe}: \mathrm{Al}_{2} \mathrm{O}_{3}=3: 1\right)$ thermally treated at $300^{\circ} \mathrm{C}$ placed from 0 to $1.5 \mathrm{~T}$ magnetic field have an excellent Faraday effects without saturation. The application of Faraday rotation of ferrofluid may be extended.

In Figure 1, in addition to the Faraday effect of ferrofluid containing Fe-Al oxide particles with mass proportion of Fe: $\mathrm{Al}_{2} \mathrm{O}_{3}=3: 1$ thermally treated at $300^{\circ} \mathrm{C}$, the other samples have inferior Faraday effects. These ferrofluids are composited by too weak magnetization intensities particles. When they are placed in the fields, the phase separation hardly happens, and the aggregation phenomena may not form. Correspondently, the ferrofluids placed in magnetic fields is similar with an isotropy system. Excellent Faraday effects couldn't be observed.

To further study the influence of the mass ratio of $\mathrm{Fe}$ to $\mathrm{Al}_{2} \mathrm{O}_{3}$ on the Faraday effects of the composite ferrofluid, a series of samples with Fe-Al oxide composite particles thermally treated at $300^{\circ} \mathrm{C}$ and having various mass ratios of $\mathrm{Fe}$ to $\mathrm{Al}_{2} \mathrm{O}_{3}$ were investigated. The experimental results are shown in Figure 2. In Figure 2, the transverse axis indicates the used magnetic field $\mathrm{B}$, and the longitudinal axis indicates the Faraday rotation angle degree of sample. The mass ratios of $\mathrm{Fe} \mathrm{Al}_{2} \mathrm{O}_{3}$ are 1:1, 1:2, 1:3, 2:1 and 3:1, respectively. In paper [25], the relationship between crystal forming of $\mathrm{Fe}-\mathrm{Al}$ oxide composite particles and the mass ratio of $\mathrm{Fe}$ versus $\mathrm{Al}_{2} \mathrm{O}_{3}$ was discussed. The larger the ratio of $\mathrm{Fe}$ to $\mathrm{Al}_{2} \mathrm{O}_{3}$ is the more $\mathrm{Fe}_{3} \mathrm{O}_{4}$ crystals of $\mathrm{Fe}-\mathrm{Al}$ oxide composite particles appear. Using the discussion above, the ferrofluid with $\mathrm{Fe}-\mathrm{Al}$ oxide composite particles at mass ratio of $\mathrm{Fe}: \mathrm{Al}_{2} \mathrm{O}_{3}=3: 1$ formed well aggregation when it is placed in a magnetic field because it may form well chains. This ferrofluid placed in field, when line polarization light passes, it has a relatively excellent Faraday effects than other samples and the curve increases more rapid than others. The Faraday rotation curves of ferrofluid

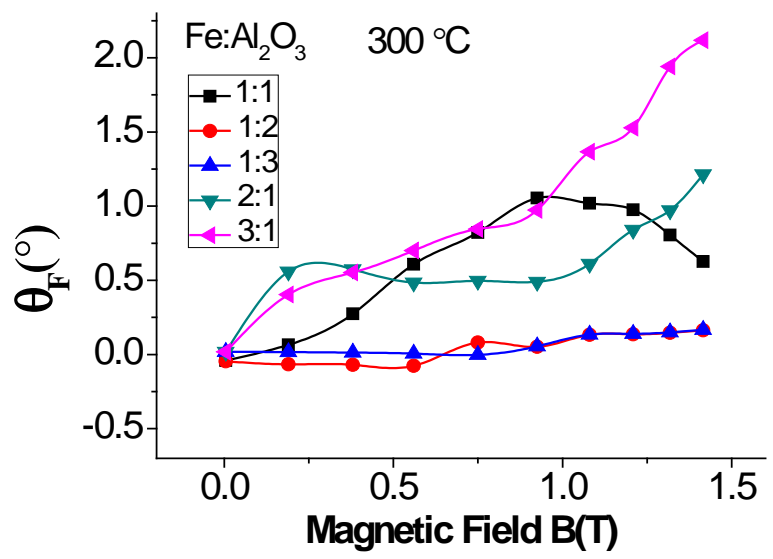

Figure 2. Faraday effects of the Fe-Al oxide composite ferrofluid. The $\mathrm{Fe}-\mathrm{Al}$ oxide composite particles were thermally treated at $300^{\circ} \mathrm{C}$ and had various mass ratios of $\mathrm{Fe}$ to $\mathrm{Al}_{2} \mathrm{O}_{3}$. 
with Fe-Al oxide particles which mass ratios of $\mathrm{Fe}$ to $\mathrm{Al}_{2} \mathrm{O}_{3}$ are 1:2, 1:3 are approximate zero. They would have little application at aspect of Faraday rotation. The Faraday rotation curves of ferrofluid with Fe-Al oxide particles which mass ratios of $\mathrm{Fe}$ to $\mathrm{Al}_{2} \mathrm{O}_{3}$ are 1:1, 2:1 are non-linearity, this phenomenon is required further study.

\section{Conclusion}

A new type of ferrofluid showing a relatively excellent Faraday effect without saturation at range $0-1.5 \mathrm{~T}$ magnetic field is synthesized. The ferrofluid containing Fe-Al oxide composite particles which mass ratio is $\mathrm{Fe}: \mathrm{Al}_{2} \mathrm{O}_{3}=3: 1$ and thermally treated at $300^{\circ} \mathrm{C}$. The Fe-Al composite oxide particles synthesized linear Faraday effect ferrofluid are gotten.

\section{Acknowledgements}

This research was supported by the United Fund Project of Guizhou province and Bijie Science and Technology burean and Bijie University (No. LKB [2012]07).

\section{References}

[1] Winter, S., Mok, C. and Kumarakrishnan, A. (2006) Tools for Laser Spectroscopy: The Design and Construction of a Faraday Isolator. Canadian Journal of Physics, 84, 845-855. http://dx.doi.org/10.1139/p06-075

[2] Gerber, R., Wright, C.D. and Asti, G., Eds. (1994) Applied Magnetism. NATO ASI Series E: Applied Sciences. Kluwer Academic, Dordrecht, $591 \mathrm{p}$.

[3] Affolderbach, C., Stähler, M., Knappe, S. and Wynands, R. (2002) An All-Optical, High-Sensitivity Magnetic Gradiometer. Applied Physics B, 75, 605-612. http://dx.doi.org/10.1007/s00340-002-0959-8

[4] Hafez, J.M., Gao, J. and Eden, J.G. (2007) Detection of Weak ( 0.5-300 nT), Low Frequency (5-100 Hz) Magnetic Fields at Room Temperature by Kilohertz Modulation of the Magneto-Optical Hysteresis in Rare Earth-Iron Garnet Films. Applied Physics Letters, 90, Article ID: 132502. http://dx.doi.org/10.1063/1.2713144

[5] Alfano, R.R. and Baird, D.H. (1968) Use of the Faraday Effect to Determine Electron Concentrations and Concentration Profiles in n-GaAs. Journal of Applied Physics, 39, 2931-2936. http://dx.doi.org/10.1063/1.1656696

[6] Gaj, J.A., Galazka, R.R. and Nawrocki, M. (1978) Giant Exciton Faraday Rotation in $\mathrm{Cd}_{1-\mathrm{x}} \mathrm{Mn}_{\mathrm{x}} \mathrm{Te}$ Mixed Crystals. Solid State Communications, 25, 193-195. http://dx.doi.org/10.1016/0038-1098(78)91477-1

[7] Zayat, M., del Monte, F., Morales, M.P., Rosa, G., Guerrero, H., Serna, C.J. and Levy, D. (2003) Highly Transparent $\gamma$ - $\mathrm{Fe}_{2} \mathrm{O}_{3} /$ Vycor-Glass Magnetic Nanocomposites Exhibiting Faraday Rotation. Advanced Materials, 15, 1809-1812. http://dx.doi.org/10.1002/adma.200305436

[8] Zhang, L., Zhang, L.S. and Xiao, S.Q. (2008) Giant Magneto-Optical Faraday Effect of Nanometer Fe- $\mathrm{In}_{2} \mathrm{O}_{3}$ Granular Films. Chinese Science Bulletin, 53, 1133-1137. http://dx.doi.org/10.1007/s11434-008-0043-9

[9] Dorman, J.L., Fiorani, D., Giammaria, F. and Lucari, F. (1990) Magnetization Measurements by Magneto-Optical Methods on Films with Fe Particles in an $\mathrm{Al}_{2} \mathrm{O}_{3}$ Amorphous Matrix. Journal of Applied Physics, 67, 5894-5896. http://dx.doi.org/10.1063/1.346006

[10] Matsuzaki, M., Kikura, H., Matsushita, J., Aritomi, M. and Akatsuka, H. (2004) Real-Time Observation of Brownian motion and Cluster Movement of Ferro- and Non-Magnetic Particles in Magnetic Fluids. Science and Technology of Advanced Materials, 5, 667-671. http://dx.doi.org/10.1016/j.stam.2004.03.012

[11] Yang, H.C., Jeang, B.Y., Yang, S.Y., Horng, H.E., Huang, T.P. and Hong, C.Y. (2002) Structure of the Magnetic Fluid Film under Alternating Magnetic Fields. Journal of Magnetism and Magnetic Materials, 252, 287-289. http://dx.doi.org/10.1016/S0304-8853(02)00733-3

[12] Taketomi, S., Takahashi, H., Inaba, N. and Miyajima, H. (1991) Experimental and Theoretical Investigations on Agglomeration of Magnetic Colloidal Particles in Magnetic Fluids. Journal of the Physical Society of Japan, 60, 16891707. http://dx.doi.org/10.1143/JPSJ.60.1689

[13] Rousan, A.A., EL-Ghanem, H.M. and Yusuf, N.A. (1989) Faraday Rotation and Chain Formation in Magnetic Fluids. IEEE Transactions on Magnetics, 25, 3121-3124. http://dx.doi.org/10.1109/20.34384

[14] Hong, H.E., Hong, C.-Y., Yang S.Y. and Yang, H.C. (2001) Novel Properties and Applications in Magnetic Fluids. Journal of Physics and Chemistry of Solids, 62, 1749-1764. http://dx.doi.org/10.1016/S0022-3697(01)00108-1

[15] Janssen, J.J.M. and Perenboom, J.A.A.J. (1989) Magneto-Optical Phenomena in Magnetic Fluids: The Influence of Orientation of Anisotropic Scatters. Journal of Magnetism and Magnetic Materials, 81, 14-24. http://dx.doi.org/10.1016/0304-8853(89)90223-0 
[16] Libaers, W., Kolaric, B., Vallée, R.A.L., Wong, J.E., Wouters, J., Valev, V.K., Verbiesta, T. and Claysa, K. (2009) Faraday Rotation in Magnetic Colloidal Photonic Crystals. Proceedings of SPIE, Volume 7467, 74670C-1.

[17] Maiorov, M.M. (2002) Faraday Effect in Magnetic Fluids at a Frequency 10GHz. Journal of Magnetism and Magnetic Materials, 252, 111-113. http://dx.doi.org/10.1016/S0304-8853(02)00661-3

[18] Yusuf, N.A., Rousan, A.A. and El-Ghanem, H.M. (1987) Determination of Faraday Rotation in a Ferrofluid. Journal of Magnetism and Magnetic Materials, 65, 282-284. http://dx.doi.org/10.1016/0304-8853(87)90052-7

[19] Donatini, F., Sahsah, H. and Monin, J. (1997) Pure Faraday Rotator: A Ferrofluid Mixing Method. Applied Optics, 36, 8165-8167. http://dx.doi.org/10.1364/AO.36.008165

[20] El-Diasty, F., El-Sayed, H.M., El-Hosiny, F.I. and Ismail, M.I.M. (2009) Complex Susceptibility Analysis of Magneto-Fluids: Optical Band Gap and Surface Studies on the Nanomagnetite-Based Particles. Current Opinion in Solid State and Materials Science, 13, 28-34. http://dx.doi.org/10.1016/j.cossms.2008.09.002

[21] Tourinho, F.A., Moraist, P.C., Sous, M.H. and Macedo, L.G. (1996) Chemical Preparation of New Magnetic Fluids Based on Spinel Ferrite Nanoparticles. Proceedings of the Third ICIM/ECSSM, Lyon, 3-5 June 1996, 317-321.

[22] Royer, F., Jamon, D., Rousseau, J.J., Zins, D., Cabuil, V., Neveu, S. and Roux, H. (2004) Magneto-Optical Properties of $\mathrm{CoFe}_{2} \mathrm{O}_{4}$ Ferrofluids: Influence of the Nanoparticle Size Distribution. Progress in Colloid and Polymer Science, 126, 155-158. http://dx.doi.org/10.1007/b94013

[23] Dai, M., Pu, S.L., Sun, G.Q. and Gu, Z.T. (2010) Giant Magneto-Optical Faraday Effect of Fe- $\mathrm{Al}_{2} \mathrm{O}_{3}$ Films Prepared by Sol-Gel Techniques. Optics Technology, 36, 535-539.

[24] Pu, S.L., Dai, M. and Sun, G.Q. (2010) Longitudinal Field-Induced Polarized Light Transmittance of Magnetic Fluids. Optics Communication, 283, 4012-4016. http://dx.doi.org/10.1016/j.optcom.2010.06.028

[25] Dai, M. and Pu, S.L. (2011) Fe-Al Oxide Composite Magnetic Nanoparticles Synthesized by Sol-Gel Method. Journal of Magnetic Materials and Devices, 42, 28-32. 